\title{
Importance of population data in forest management planning
}

\author{
by Dale R. McCullough
}

Recent shifts in emphasis to preservation of biological diversity and establishment of large nature reserves have resulted in downgrading of the perceived importance of data at the population level. These shifts in emphasis, while laudable, should not result in loss of focus on the fundamental importance of population information. Suitable habitat, although a prime necessity, is not sufficient for wildlife preservation. Species may not occupy otherwise suitable habitat because of internal (predation, interspecific competition, disease) or external (adverse climate, exploitation, disturbance, impact of exotic species, pollution and toxicants) factors. Historical impacts may persist for many years, and may require active restoration. Forest management plans must consider population data on a metapopulation scale. Data for common species can be at the reconnaissance level whereas for threatened or sensitive species they need to be more detailed. To evaluate sustainability, population data must be integrated with forest stand data in projection models to predict habitat-population mosaics at various times in the future. These models must be developed and improved over time in an adaptive management approach.
Les récents changements touchant l'intérêt accru pour la préservation de la diversité biologique et pour la création de vastes réserves naturelles ont entraîné une dégradation de l'importance perçue des données au niveau des populations. Cet accroissement de l'intérêt, bien que légitime, ne devrait pas résulter en une dispersion de l'attention rattachée à l'importance fondamentale de l'information sur les populations. Un habitat adéquat, même s'il constitue un élément primordial, n'est pas suffisant pour préserver la faune. Une espèce pourrait ne pas occuper un habitat qui lui serait en d'autres circonstances adéquat à cause de facteurs internes (prédation, compétition inter-spécifique, maladie) ou externes (climat inapproprié, exploitation, perturbation, impact d'espèces exotiques, pollution et éléments toxiques). Les impacts historiques peuvent persister plusieurs années, et peuvent nécessiter une restauration planifiée. Les plans d'aménagement forestier doivent considérer les données sur une population à un niveau touchant l'ensemble des populations. Les données concernant les espèces communes peuvent être constituées au niveau de la reconnaissance tandis que les données sur les espèces menacées ou sensible se doivent d'être plus précises. Afin d'évaluer la durabilité, les données sur les populations doivent être intégrées avec les données se rapportant aux peuplement forestiers au sein de modèles de prédiction des mosaïques habitats-populations à divers moments dans l'avenir. Ces modèles doivent être élaborés et améliorés dans le temps afin d'en arriver à une approche d'aménagement évolutive.

\section{The Changing World}

Today we citizens of planet earth are on the threshold of a new century. The sweep of time, as illuminated by geological, paleontological, archeological, and recorded history, shows that our planet has undergone continuous, and at times revolutionary change. The apparent stability of earth is an illusion of the brief flicker in time of the individual life, of the shortness of our vision, and of the need to surround ourselves with a cocoon of predictability.

It is not enough to simply acknowledge that change is inevitable. We must confront the stark fact that the next century will be like no other before it. For what is changing most is the rate of change, that is constantly accelerating. Society had millions of years to absorb the mystery of fire, and to fumble forward with stone age implements. It had 10,000 years with bronze and iron. The formation of states took about 1000 years, and the industrial revolution about 100 years. The personal computer revolution took 10 years, and faxes about one year. These days science fiction is little more than science waiting to happen. The planet is in another period of revolutionary change.

Consider the things that are entirely new to earth's experience. We have accumulated 5 billion human beings and are rapidly surging towards 6 billion. Communication across the globe is virtually instantaneous. People throughout the world watch CNN and BBC simultaneously. Wars are watched on TV by the people

Department of Environmental Science, Policy, and Management and Museum of Vertebrate Zoology, University of California, Berkeley, CA, 94720, USA. who wage them. Individuals can communicate with other individuals across continents by fax. The English language has become the de facto standard, and all of the next generation will know it. Often it is easier to communicate with a colleague in China than with one's own teenage kid. Synthetic chemicals and acid emissions are altering our atmosphere and climate, and toxicants and radioactive materials are contaminating our soils and waters. We are husbanding fossil energy reserves with all the wisdom of a drunken sailor. We have a world community (albeit with a lot of feuding neighbours), a world economy, and a global marketplace. This revolution on planet earth is a grand experiment with no replication, no control (in multiple meanings of the word), and a sample size of one. God help us.

\section{The Changing Profession}

It is a delusion to think that our efforts as wildlife or other natural resource management professionals can produce stasis in the face of this revolution. The utopian ideal of a stable ecosystem producing an even flow of useful products for a stationary human population is a moral statement, the ecological equivalent of the religious paradise: uplifting, righteous, and unattainable. This Eden, if it ever existed, disappeared long ago. I wonder if it ever existed outside of the human mind as wishful thinking. For countless generations life has been hard and death early. If any generation has had an easy life, it surely has been in recent times. Meanwhile, the planet hurls onward through space, oblivious to the affairs of humans. And the populace grows weary of the seemingly endless succession of ecological prophets proclaiming "Repent, the end is near." Colleagues, so is the beginning. 
I believe ecology, and more specifically, resource management, must abandon its morbid fixation on endings, and refocus on the beginnings. The world will change. We must convolve if we are to be relevant and have any impact on the outcome. Otherwise we will be overrun by events and left hopelessly obsolete. Most resource professionals were trained with a management paradigm in which management is logical, linear, has no surprises, is in the public interest, and actually happens. For resources in the field, first you inventory, then decide net annual increment, then decide harvest rate, then develop a harvest plan, and finally you convince the harvesters, processors, consumers, politicians, and public of the wisdom of your actions.

I doubt whether this paradigm applies in today's world. I think an appropriate analogy is that we are being carried along by a mighty river, too big to dam and too fast to swim against. The best we can do is keep our heads up, and look downstream to see what is coming. This view concedes that we are engulfed in forces beyond our control and which we cannot manage. Staying in the same place is not a viable option. Only by looking downstream can we perceive our longer-term options, and work towards attainable ends.

\section{The Changing Forest}

Today we recognize that forests are more than timber and wildlife is more than game. Still, we are better at dealing with forest resources as single commodities than we are with forests as producers of goods and services. How much more are people willing to pay for a house in order to have large oldgrowth reserves for spotted owls and other interior species? What sort of pressure does preservation in the United States put on forests in other countries and other continents, and what loss of biological diversity will that engender? The sheer magnitude of these questions renders them beyond current technological answers, much less management solutions. But if wildlife and other natural resource professionals shy from these questions because they are technologically intractable, who will address them? Who will state a vision of what the forests of our states, provinces, countries, and the world should look like in a conceivable future time, say that of our grandchildren or great-grandchildren.

Today unconverted landscapes have become exceedingly rare, and fragmentation is the rule. Pristine forest lands have contracted, and outside of a few northern regions, become scarce. Wilderness, that foreboding and inhospitable landscape of the bible and adversary of the pioneer, has been caged, its claws trimmed and fangs removed. These days, most wilderness areas are dangerous only if leavened with human stupidity. Indeed, an expedition to the average inner city is fraught with far more danger. I suppose that there is a limit to the amount of danger we wish to encounter in a wilderness experience. But its total absence removes the illusion if not substance of following in the footsteps of Boone, Carson, MacKenzie or Smith. And at least some of us need a place where we can go to nurture that atavistic spark of wolf in our persona for fear of becoming registered cocker spaniels.

Forest conversion was not all bad. Forest conversion disfavoured the original set of wild species, and favoured an entirely different set, often including a number of exotics. So long as there was a reasonable balance between converted lands and wild lands, the conversion enriched and diversified the landscape. The new species, primarily subclimax-adapted, had their own inherent value, and conveniently, many were fast-growing valuable trees and game species.

This whole process occurred centuries ago in Europe, and forests there have seen many cycles of harvest and regeneration. Old World forests show that the production of wood and game can be sustained, and that they can be sustained in pleasing landscapes. But what is missing are those pristine areas where one can say, "This is the way it was." And many sensitive species that depended on the pristine landscape were extirpated.

In North America, the next several decades will determine whether our landscapes will include continents of pristine forests or if they will consist only of islands in a vast ocean of second growth. We have focused so intently on rare species, rare plants, rare habitats that we have largely overlooked that it is the totality of such things that has become rare. Perhaps that is why issues such as conservation of the northern spotted owl have generated such a response in the public body. If it were simply owls versus economic livelihood of timber-based local economies, owls would mostly lose in the inevitable compromise solutions that is embedded in the sociopolitical mechanism by which the decision will be reached. However, the owl is symbolic of the larger issues. By some subliminal process, our society seems to have recognized that things have changed and it is a new day. The end of virgin forest is in sight. But, so is the economic structure of local timber-based communities overrun by changes in the timber industry, products and processes, and a world marketplace.

The professions of forestry and wildlife management have accomplished wonders in their brief history. Foresters have established new forests on cutover lands, established regulations that protect soils and waters on lands to be harvested, and assured that regeneration will be seen to. Wildlife managers have restored many species to impressive abundance, and generally controlled hunting to sustainable levels. We have protected many threatened species.

We have done well with few people and small budgets while facing powerful economic interests. But while we have fought for a habitat here and a threatened species there, we have failed to adequately recognize that we are losing the larger war. Given our ideal stable and harmonious ecosystem and our management paradigm, we have struggled mightily to maintain the status quo, so much so that we have failed to look downstream. But why look downstream if you think the status quo can be maintained, and downstream will be like upstream? Only when we admit we are being carried along by larger forces does looking downstream make sense. We have been so intensely involved with movement in time issues, that we have not had time to see where it all was leading.

Most thoughtful resource professionals now concede that their professions have to change to meet the new challenges. Upstart movements such as conservation biology and preservation of biological diversity have stolen our thunder. To some extent this has come from identifying some overlooked areas: that genetics are an issue, and that small, homely species need love too. But the most important reason, I believe, is that these movements espoused the downstream view: in short, exactly that area in which the professions failed.

Colleagues, do not despair. The day is young, and if we assume the initiative, these areas can be incorporated into the profes- 
sions. After all, what are the new approaches but re-articulations of the paradise ideal, once again uplifting, righteous, and unattainable. They are emanating largely from the academic world whose life blood is rhetoric, but whose know-how and tolerance for the political-social world is minimal. If these approaches are to move beyond the realm of talk and into the realm of implementation, it will be the professions that must carry them.

\section{Preserving Biological Diversity: Are Population Studies Obsolete?}

Preservation of biological diversity emphasizes saving all species, and reserve design criteria from conservation biology gives a series of rules for size and placement of reserves for maximum effectiveness. Even the wildlife profession has shifted to an emphasis towards ecosystem management and away from species management.

Suitable habitat is the fundamental prerequisite for existence of wildlife. Without habitat there will be no wildlife. Therefore, the predominant emphasis on habitat management in wildlife management plans, which is traditional in the field, is appropriate. Habitat preservation, restoration, and enhancement must continue to be the first and foremost concern in wildlife conservation and management. Without habitat, there can be no populations. The recent book by Morrison et al. (1992) gives a convenient review of this complex topic.

Where, then, does this leave work at the population level of inquiry? Are these idle luxuries for the intellectually curious? Are they vestiges of an earlier time when habitats were pristine and intact, and animals were scarce because of uncontrolled exploitation? Are population level concerns obsolete, a reflection of fixation of humans on a few economically important or charismatic species to the detriment of myriad of obscure species, and more fundamentally, the complex ecosystems that sustain all life? Is it time to relegate population studies to the dustbins of history and get on exclusively with habitat level studies?

Some individuals would say yes to these questions as a basic position. Others would say yes out of frustration with the current patterns of funding allocation in which a few charismatic endangered species receive enormous amounts of money, whereas funds for habitat acquisition, restoration, and protection are woefully inadequate given the accelerating rate at which the face of the earth is being altered. The work of habitat preservation is more diffuse as compared to the highly visible efforts on populations or endangered species, and usually much less glamorous, attracting far less media coverage and public attention.

Although habitat preservation is necessary, it is not sufficient. Indeed, it is species populations of plants by which habitats, and biological reserves, are recognized. In a way, trying to isolate habitat as distinct from populations is like representing the body as anatomy without physiology. They are simply different ways of viewing the same entity, and the entity is by no means complete and functional without all of its life functions, including those carrying the traditional label of populations.

More realistic is the view that habitat preservation will automatically preserve the species of plants and animals contained therein. While preservation of habitat as a strategy for conservation is superior to any other single strategy, it too is incomplete for reasons discussed by O'Neil and Carey (1986).
Some suitable habitats might not contain species that ordinarily would occur in those habitats. They may be absent because of competition (Diehl 1986), predation, exploitation if they are a hunted or commercially important species, or they may have recently suffered a catastrophe due to adverse weather (O'Connor 1986), a virulent disease, flood or similar event.

Some species naturally show great fluctuations in population size and local extinction may be a common occurrence. In the fragmented habitats of the modern world, sources of recolonization may be unavailable. Recent interest in metapopulation approaches has developed because of the number of species that behave in this manner. Although they typically are small, and r-selected, this is not necessarily so, and for example, some studies of metapopulation dynamics have been applied to sharp-tailed grouse (Tympanuchus phasianellus) (Temple 1992), capercaillie grouse (Tetrao urogallus) (Wegge et al. 1992), and seabird colonies (Buckley and Downer 1992). Populations in continuous habitat that ordinarily do not depend on colonization (that is, immigration and emigration are local in scale), may behave like metapopulations as continuous habitats become fragmented. Similarly, populations that show relative stability in continuous habitat may become fluctuating in isolated habitat patches.

Island biogeographic theory (MacArthur and Wilson 1967) emphasizes the importance of size of area as a variable influencing the likely persistence of species, with extinction becoming more likely as size of area declines. The gross scale on which this theory has been applied has ignored the habitat elements and led to some questionable conclusions. We know that some small areas with high habitat diversity contain more species than some much larger areas with homogenous habitats. Nevertheless, within habitats, size of patch is an obviously important variable. However, different species populations may not show a continuously variable relationship to patch size. It is more likely that there are thresholds in size below which an area cannot meet the ecological requirements of the species.

Numerous attempts to model habitat relationships have been made, and conveniently, these have been summarized in a symposium (Verner et al. 1986). We now have reasonable empirical tests of the use of habitat models to predict occurrence of species. Such models often have failed (Dedon $\mathrm{et} \mathrm{al}$. 1986, Laymon and Barrett 1986, Raphael and Marcot 1986, others). Although some authors report that models were successful on limited areas with a few taxa (Rice et al. 1986), others report failure under similar conditions (Capen et al. 1986, Rotenberry 1986, Kellner et al. 1992). Predictions fail when species present in a habitat are not predicted, and when species predicted to be present are not. These failures trace to both inadequacy of the sampling schemes (a solvable problem) and to the variation in nature of species distributions, an intractable problem, a problem residing at the population level of study.

\section{The Continuing Need for Population Information}

If models were successful in predicting the presence or absence of species in given habitats, there would be little need to obtain further population information. The argument for the obsolescence of population work could be sustained. The failure of habitat models to predict at even this elementary level highlights the need for population information beyond simple 
presence or absence. Building models predicting such dynamics requires more detailed data. Why do some populations show such great flux over time and space? That they do emphasizes the need for a metapopulation approach, because extinction in local habitats can be reversed only by recolonization from other habitat patches. Species dependent on metapopulation structure for persistence over time has grave consequences for the forest management scheme and how it impacts the patch dynamics of habitats over time.

Population studies over most of the short history of wildlife management have been taken to mean autecological studies with high cost and effort over a limited spatial scale. Such intensity of study is necessary given the complexity of population dynamics. These studies form the basic understanding we have of population processes, and they continue to make legitimate and necessary advances to the field. However, they usually do not address the needs for population data necessary to the building and testing of predictive models useful in habitat planning and management. These efforts require population data at the monitoring level, and time and cost considerations limit the detail that it is reasonable to obtain. But even reconnaissance techniques by a good naturalist are sufficient to place species in abundance categories, such as absent, rare, common or abundant. Monitoring and inventory are still in early stages of development, and the development of indices to population abundance (i.e., easily obtained measures that are consistently correlated with population abundance) holds considerable promise. For common and widespread species, population data at this level are probably sufficient. Sensitive, threatened, and endangered species will require more attention because their limited abundance and distribution will not be sampled adequately in a broadscale monitoring effort, and the consequence of mistakes may be extinction. Population specialists and habitat specialists are natural allies. Where better to test monitoring techniques and evaluate indices than in areas where population biologists have already determined population size at a finer resolution. And the population biologist is dependent on the habitat specialist to obtain information on metapopulation-scale phenomena.

\section{Planning on a Regional Scale}

At the beginning of this paper I argued for a downstream view of forest and wildlife habitat planning. Only such a view will allow us to determine if future landscape mosaics will contain those commodities, services and values we want for society. Projection models, despite their shortcomings, are the only realistic way of peering into the future to see what the distant consequences of our current policies, plans, and actions will be.

Given the failings of current habitat models, and the multiplicative combining of independent variances of variables in building large-scale models, it would be easy to be unduly pessimistic about developing models of any usefulness. But the broad scale and long-time frames of such models casts the use of such models in a different light. Current models fail by not correctly predicting species composition in given habitat patches. But to evaluate the landscape mosaics at, say 50 or 100 years in the future, it is not so important what the species composition is in a given patch. More important is the number, size and distribution of such patches. Then if the model predicts a species occurrence correctly, for example $65 \%$ of the time for each patch, the probability of the number of patches present and whether they can function in metapopulation fashion for the species of concern can be used to estimate likelihood of persistence of that species in the landscape. Too few patches, or patches too isolated from each other would be cause for concern.

If in addition, population abundance measures could be built into such models, the prediction of abundance could be projected along with a prediction of occurrence. Then the combined probabilities of occurrence and abundance could be used to evaluate the adequacy of the mosaic to sustain a given species. Few habitat patches, low probability of occurrence, and low abundances would be red flags for potential extinction, and the need to reevaluate management plans.

Few models at this scale are being attempted at present. Barrett et al. (1992) have begun such an effort in northern California, but it does not include population abundance information, only species occurrence. Nonetheless, projections of their model (Fig. 1) show the likely consequence of current management plans at various times in the future for the forest mosaic, and suggest candidate species of concern given such changes. Models such as this point the way, although everyone would agree that they have a long way to go before they approach their potential.
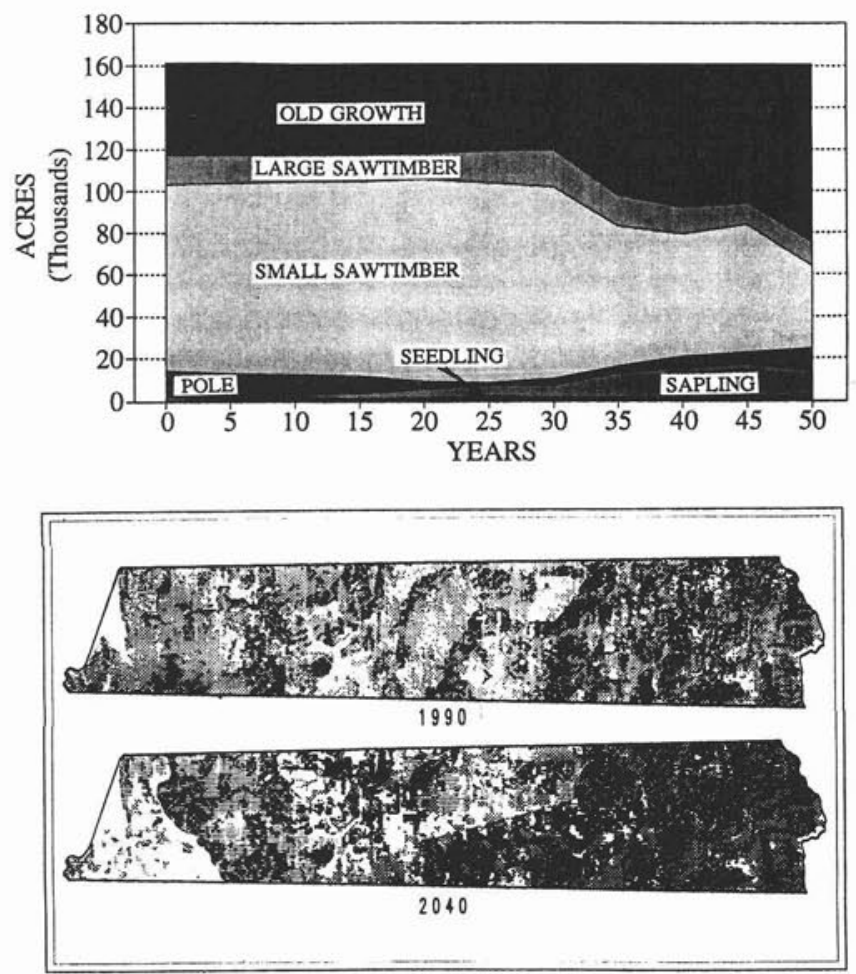

Figure 1. Projection model of changes in size class distribution of wildlife habitat over 50 years under current policies in a 160,000 ha area in northern Humboldt County, California (above) and changes in habitat suitability for the pileated woodpecker (Dryocopus pileatus) associated with these changes (below). Habitat suitability is indicated by darkness of shading with dark being high, and white being none. Habitat suitability for the pileated woodpecker is projected to increase over the next 50 years under current forest management policies because of this species' preference for old growth. The projection area includes 6 major landowner categories. After Barrett et al. 1992. 
Not the least value of such models is that their predictions demand some kind of evaluation. They force the process of adaptive management (Walters 1986) to begin. Some people will like the predicted outcome and others not. The parameters and functions of the models will be challenged. Data on questionable issues will be marshalled from files, and new studies will be conducted. Research will be guided by clear need rather than what administrators think, or interest groups demand. There will be debate. Over time, the data will become stronger, the models will evolve, and the sociopolitical system will articulate a clearer definition of what we want the forests and wildlife of the future to be like. Then perhaps downstream will be more than a place we are carried by the currents; it might be a place we want to go.

\section{Acknowledgments}

I wish to thank R.H. Barrett and L.S. Davis for allowing me to use the unpublished information in Figure 1.

\section{References}

Barrett, R.H., L.S. Davis, I. Timossi, F. Schurr, S. Miller and W. Legard. 1992. North coast wildlife pilot study. pp. 1-40. In The report of the California Timberland Task Force, submitted to the California Legislature, Sacramento. Appendix.

Buckley, P.A. and R. Downer. 1992. Modeling metapopulation dynamics for single species of seabirds. pp. 563-585. In Wildlife 2001: Populations. D.R. McCullough and R.H. Barrett (eds.). Elsevier Science Publishers, Ltd., London.

Capen, D.E., J.W. Fenwick, D.B. Inkley and A.C. Boynton. 1986. Multivariate models of songbird habitat in New England forests. pp. 171-175. In Wildlife 2000: Modeling habitat relationships of terrestrial vertebrates. J. Verner, M.L. Morrison and C.J. Ralph (eds.). University of Wisconsin Press, Madison.

Dedon, M.F., S.A. Laymon, and R.H. Barrett. 1986. Evaluating models of wildlife-habitat relationships of birds in black oak and mixedconifer habitats. pp. 115-119. In Wildlife 2000: Modeling habitat relationships of terrestrial vertebrates. J. Verner, M.L. Morrison and C.J. Ralph (eds.). University of Wisconsin Press, Madison.

Diehl, B. 1986. Factors confounding predictions of bird abundance from habitat data. pp. 229-233. In Wildlife 2000: Modeling habitat relationships of terrestrial vertebrates. J. Verner, M.L. Morrison and C.J. Ralph (eds.). University of Wisconsin Press, Madison.

Kellner, C.J., J.D. Brawn and J.R. Karr. 1992. What is habitat suitability and how should it be measured? pp. 476-488. In Wildlife 2001: Populations. D.R. McCullough and R.H. Barrett (eds.). Elsevier Science Publishers, Ltd., London.
Laymon, S.A. and R.H. Barrett. 1986. Developing and testing habitat-capability models: pitfalls and recommendations pp. 87-91. In Wildlife 2000: Modeling habitat relationships of terrestrial vertebrates. J. Verner, M.L. Morrison and C.J. Ralph (eds.). University of Wisconsin Press, Madison.

MacArthur, R.H., and E.O. Wilson. 1967. The theory of island biogeography. Princeton University Press, Princeton, New Jersey. p. 203. Morrison, M.L., B.G. Marcot and R.W. Mannan. 1992. Wildlifehabitat relationships: Concepts and applications. University of Wisconsin Press, Madison.

O'Connor, R.J. 1986. Dynamical aspects of avian habitat use. pp. 235-240. In Wildlife 2000: Modeling habitat relationships of terrestrial vertebrates. J. Verner, M.L. Morrison and C.J. Ralph (eds.). University of Wisconsin Press, Madison.

O'Neil, L.J. and A.B. Carey. 1986. When habitats fail as predictors. pp. 207-208 In Wildlife 2000: Modeling habitat relationships of terrestrial vertebrates. J. Verner, M.L. Morrison, and C.J. Ralph (eds.). University of Wisconsin Press, Madison.

Raphael, M.G. and B.G. Marcot. 1986. Validation of a wildlife-habitatrelationships model: Vertebrates in a Douglas-fir sere. pp. 129-138. In Wildlife 2000: Modeling habitat relationships of terrestrial vertebrates. J. Verner, M.L. Morrison, and C.J. Ralph (eds.). University of Wisconsin Press, Madison.

Rice, J.C., R.D. Ohmart and B.W. Anderson. 1986. Limits in a datarich model: Modeling experience with habitat management on the Colorado River. pp. 79-86 In Wildlife 2000: Modeling habitat relationships of terrestrial vertebrates. J. Verner, M.L. Morrison, and C.J. Ralph (eds.). University of Wisconsin Press, Madison.

Rotenberry, J.T. 1986. Habitat relationships of shrubsteppe birds: even "good" models cannot predict the future. pp. 217-221. In Wildlife 2000: Modeling habitat relationships of terrestrial vertebrates. J. Verner, M.L. Morrison and C.J. Ralph (eds.). University of Wisconsin Press, Madison.

Temple, S.A. 1992. Population viability analysis of sharp-tailed grouse metapopulation in Wisconsin. pp. 750-758. In Wildlife 2001: populations. D.R. McCullough and R.H. Barrett (eds.). Elsevier Science Publishers, Ltd., London.

Verner, J., M.L. Morrison and C.J. Ralph (eds.). 1986. Wildlife 2000: Modeling habitat relationships of terrestrial vertebrates. University of Wisconsin Press, Madison.

Walters, C.J. 1986. Adaptive management of renewable resources. Macmillan, New York.

Wegge, P., J. Rolstad and I. Gjerde. 1992. Effects of boreal forest fragmentation on capercaillie grouse: empirical evidence and management implications. pp. 738-749. In Wildlife 2001: Populations. D.R. McCullough and R.H. Barrett (eds.). Elsevier Science Publishers, Ltd., London. 